\title{
Insulin Resistance in Obese Zucker Rat (fa/fa) Skeletal Muscle Is Associated with a Failure of Glucose Transporter Translocation
}

Patricia A. King, Elizabeth D. Horton, Michael F. Hirshman, and Edward S. Horton

Department of Medicine, University of Vermont, Burlington, Vermont 05405

\begin{abstract}
The genetically obese Zucker rat ( $\mathrm{fa} / \mathrm{fa}$ ) is characterized by a severe resistance to the action of insulin to stimulate skeletal muscle glucose transport. The goal of the present study was to identify whether the defect associated with this insulin resistance involves an alteration of transporter translocation and /or transporter activity. Various components of the muscle glucose transport system were investigated in plasma membranes isolated from basal or maximally insulin-treated skeletal muscle of lean and obese Zucker rats. Measurements of D- and L-glucose uptake by membrane vesicles under equilibrium exchange conditions indicated that insulin treatment resulted in a fourfold increase in the $V_{\max }$ for carrier-mediated transport for lean animals [from 4.5 to $17.5 \mathrm{nmol} /(\mathrm{mg} \cdot \mathrm{s})$ ] but only a 2.5 -fold increase for obese rats [from 3.6 to $9.1 \mathrm{nmol} /(\mathrm{mg} \cdot \mathrm{s})$ ]. In the lean animals, this increase in glucose transport function was associated with a 1.8-fold increase in the transporter number as indicated by cytochalasin B binding, a 1.4-fold increase in plasma membrane GLUT4 protein, and a doubling of the average carrier turnover number (intrinsic activity). In the obese animals, there was no change in plasma membrane transporter number measured by cytochalasin B binding, or in GLUT4 or GLUT1 protein. However, there was an increase in carrier turnover number similar to that seen in the lean litter mates. Measurements of GLUT4 mRNA in red gastrocnemius muscle showed no difference between lean and obese rats. We conclude that the insulin resistance of the obese rats involves the failure of translocation of transporters, while the action of insulin to increase the average carrier turnover number is normal. ( $J$. Clin. Invest. 1992. 90:1568-1575.) Key words: glucose transport • GLUT4 • plasma membrane
\end{abstract}

\section{Introduction}

The genetically obese Zucker rat $(\mathrm{fa} / \mathrm{fa})$ is a model of insulin resistance characterized by hyperinsulinemia, obesity, and hyperlipidemia in association with glucose intolerance $(1,2)$. The peripheral insulin resistance observed in these animals results largely from an impairment of insulin-stimulated glucose uptake into skeletal muscle, the major site of insulin-mediated glucose disposal $(3,4)$. Multiple abnormalities in the cellular

Part of this research was published in abstract form at the 1990 Annual Meeting of the American Diabetes Association.

Address reprint requests to Dr. King, Department of Medicine, University of Vermont, Burlington, VT 05405. 1992

Received for publication 11 April 1991 and in revised form 20 April

J. Clin. Invest.

(C) The American Society for Clinical Investigation, Inc.

$0021-9738 / 92 / 10 / 1568 / 08 \quad \$ 2.00$

Volume 90, October 1992, 1568-1575 physiology of insulin-mediated glucose disposal are associated with the insulin resistance including alterations in insulin binding, glucose metabolism, and glucose transport (3-6). Of these, defects in the glucose transport system appear to be a major causal factor. It has been consistently observed that obese Zucker rat skeletal muscle glucose transport, whether measured by glucose uptake in perfused hindlimb (3), 2-deoxyglucose uptake in isolated soleus muscle (4), or 3-0-methyl glucose transport in hindlimb (6), is characterized by a lower rate of uptake in the absence of insulin and a decreased response to maximal insulin stimulation as compared to transport by skeletal muscle of the lean litter mates ( $\mathrm{Fa} /$ ?).

The action of insulin to stimulate glucose transport in skeletal muscle is thought to involve two processes. The first is an increase in the number of transporters in the plasma membrane via recruitment from an intracellular pool as identified by an increase in plasma membrane cytochalasin B binding, concomitant with a decrease in the binding of an intracellular membrane pool (7-10). More recently the increase in plasma membrane glucose transporter number has been shown to be recruitment of the specific muscle/adipose isoform of the glucose transporter (GLUT4) (10-12). The second observed action of insulin is to increase the average turnover number (activity) of the transporters in the plasma membrane, but it is unknown whether this process involves a modification of the transporter directly or the recruitment of a more active isoform $(9,13)$.

Although the glucose transport system is thought to be the major site of insulin resistance in the obese Zucker rat skeletal muscle, it is not known which step(s) is defective in the sequence of events that normally effects the increase in glucose transport in response to the hormone. A number of recent studies have examined the relationship of muscle glucose transporter expression to alterations in glucose transport and the cellular response to insulin, focusing on the measurement of total transporter protein and mRNA levels in animal models of insulin resistance, including the obese Zucker rat (14-16). In general, the results indicate that in vivo insulin resistance can occur without changes (or with increases) in skeletal muscle transporter protein levels, thus leading to the conclusion that the insulin resistance reflects an alternate defect, possibly transporter translocation or activity. The purpose of the present study was to determine if transporter recruitment and/or transporter activity are altered in muscle of obese Zucker rats. To do this, the glucose transporter system was investigated in plasma membranes isolated from skeletal muscle of basal vs. maximally-stimulated lean and obese Zucker rats. Measurements of transporter number and isoform and the average carrier turnover number were made. Our results indicate that the insulin resistance of the obese Zucker rat muscle is associated with a failure of translocation of transporters to the plasma membrane while the action of insulin to increase the average carrier turnover number is intact. 


\section{Methods}

Animals. Obese (fa/fa) and lean ( $\mathrm{Fa} /$ ?) Zucker rats, obtained from Charles River Breeding Laboratories, Wilmington, MA, were housed in a room maintained at $23^{\circ} \mathrm{C}$ with a 12 -h light-dark cycle and fed ad libitum for at least $6 \mathrm{~d}$ before the experiment. Animals used in the experiments were 10-12 wk old with an average weight of $223 \pm 7 \mathrm{~g}$ (mean \pm SE, range $200-256 \mathrm{~g}$ ) for the lean and $400 \pm 9 \mathrm{~g}$ (mean $\pm \mathrm{SE}$, range $355-450 \mathrm{~g}$ ) for the obese. Postprandial animals were investigated under basal physiological conditions or under conditions of maximal insulin stimulation. Insulin treatment was achieved by intraperitoneal injection of insulin ( $10-20 \mathrm{U}$ ) $30 \mathrm{~min}$ before killing the animals. The basal animals were handled but received no i.p. injection. The animals were killed by decapitation and blood was collected for glucose and insulin measurement. The gastrocnemius muscle was then quickly exposed and $\sim 6 \mathrm{~g}$ of muscle (soleus, red, and white gastrocnemius) were rapidly dissected, taking care to remove fat and connective tissue.

Membrane preparation. The method for preparing plasma membranes was derived from the methods of Bers (17) and Grimditch et al. (18) as modified by Hirshman et al. (10). The dissected muscle was minced and homogenized in $255 \mathrm{mM}$ sucrose, $0.2 \mathrm{mM}$ EDTA and 100 $\mathrm{mM}$ Tris, $\mathrm{pH} 7.6$ at $4^{\circ} \mathrm{C}$, by polytroning and homogenization in a Potter-Elvejhem homogenizer. After low speed centrifugation $(48,000$ $g$ for $20 \mathrm{~min}$ ) the pellet was resuspended in $250 \mathrm{mM}$ sucrose and 20 $\mathrm{mM}$ Hepes, $\mathrm{pH} 7.4$, and $\mathrm{KCl}$ and sodium pyrophasphate were added to make the final concentrations 300 and $25 \mathrm{mM}$, respectively. After centrifugation, the resuspended pellet was incubated with DNAase, recentrifuged, and the pellet resuspended for centrifugation in a sucrose gradient. The plasma membranes were collected from the $12 / 27 \%$ and $27 / 30 \%$ sucrose interfaces. The membranes were pelleted by centrifugation and resuspended in the sucrose buffer to a final protein concentration of $2-4 \mathrm{mg} / \mathrm{ml}$. The membranes were stored in liquid $\mathrm{N}_{2}$ until use.

Enzymes. Samples from the original whole homogenates and the final membranes were taken for measurement of K-stimulated $p$-nitrophenyl phosphatase activity (K-pNPPase, 17) and $\mathrm{Ca}^{2+}$ ATPase activity (19), enzyme markers for the plasma membrane and sarcoplasmic reticulum, respectively. Proteins were measured by the Coomassie Brilliant Blue method (Bio-Rad protein assay, Bio-Rad Laboratories, Richmond, CA) described by Bradford (20).

Cytochalasin B binding. Equilibrium D-glucose inhibitable $\left[{ }^{3} \mathrm{H}\right]-$ cytochalasin $B$ binding was measured, and the concentration of glucose transporters was calculated as described by Wardzala et al. (21). Scatchard plots were generated from binding studies in which membranes were incubated with varying concentrations of cytochalasin B in the presence or absence of $500 \mathrm{mM}$ D-glucose. Cytochalasin $\mathrm{E}$ was used to decrease nonspecific binding. The total number of transporters $\left(R_{\mathrm{o}}\right)$ and the dissociation constant $\left(K_{\mathrm{d}}\right)$ were determined from a linear plot derived by subtracting along the radial axes of binding curves generated in the presence of D-glucose from those in the absence of D-glucose.

Transport measurements. $\mathrm{D}-\left[{ }^{14} \mathrm{C}\right]$ glucose and $\mathrm{L}-\left[{ }^{3} \mathrm{H}\right]$ glucose uptake into membrane vesicles were measured under conditions of equilibrium exchange using a rapid filtration technique as previously described by King et al. (13). The transport medium contained $135 \mathrm{mM}$ $\mathrm{NaCl}, 5 \mathrm{mM} \mathrm{KCl}, 1.2 \mathrm{mM} \mathrm{MgCl}{ }_{2}$ and $20 \mathrm{mM}$ Hepes, $\mathrm{pH} 7.4$ at $25^{\circ} \mathrm{C}$, and equal concentrations of $\mathrm{L}$ - and D-glucose (1-60 mM). The incubation media included $6 \mu \mathrm{Ci} / 80 \mu \mathrm{L}-\left[1-{ }^{3} \mathrm{H}\right]$ glucose $(20 \mathrm{Ci} / \mathrm{mmol})$ and $1.6 \mu \mathrm{Ci} / 80 \mu \mathrm{l} \mathrm{D}-\left[{ }^{14} \mathrm{C}\right]$ glucose $(265 \mathrm{mCi} / \mathrm{mmol})$, both from New England Nuclear-DuPont, Boston, MA. Uptake was initiated by combining the vesicles and incubation medium and was routinely measured at four time points between 0 and $5 \mathrm{~s}$ for membranes from basal animals and between 0 and $2 \mathrm{~s}$ for membranes from insulin-treated rats. The reaction was stopped by addition of $1 \mathrm{ml}$ of ice-cold stop solution ( 250 $\mathrm{mM} \mathrm{NaCl}, 5 \mathrm{mM} \mathrm{KCl}, 1.2 \mathrm{mM} \mathrm{MgCl}_{2}, 20 \mathrm{mM}$ Hepes, $\mathrm{pH} 7.8$ at $4^{\circ} \mathrm{C}$ ) containing $0.2 \mathrm{mM}$ phloretin and the membranes were quickly transferred to a nitrocellulose filter (Millipore Corp., Bedford, MA; HA 0.45 $\mu \mathrm{m})$ under vacuum. The filter was washed and analyzed by liquid scintillation counting, using quench correction for a dual label.

The initial rates of L- and D-glucose uptake were obtained from the linear portion of a graph of influx (in nanomoles per milligram of protein) versus time and the carrier-mediated or facilitated transport was obtained by subtracting the initial rate of $L$-glucose influx from that of D-glucose. The rates of carrier-mediated influx were then graphed versus glucose concentration ( $1-60 \mathrm{mM}$ ) and a $V_{\max }$ and $K_{1 / 2}$ obtained by a nonlinear least-squares fit (22) of the data.

Western blots. Plasma membrane protein $(20 \mu \mathrm{g})$ and molecular weight markers (Bio-Rad Laboratories) were subjected to SDS-PAGE and resolved proteins were electrophoretically transferred to nitrocellulose $(23,24)$. Incubations were carried out in Tris-buffered saline, 20 $\mathrm{mM}$ Tris, $500 \mathrm{mM} \mathrm{NaCl}, \mathrm{pH} 7.5$ at $22^{\circ} \mathrm{C}$, unless otherwise indicated. The nitrocellulose transfer membranes were blocked in Tris-buffered saline with $0.2 \%$ Tween 20 and 5\% carnation nonfat dry milk. To identify GLUT4 or GLUT1 proteins, the transfer membranes were incubated with either the polyclonal antibody $\mathrm{R} 820(4 \mu \mathrm{g} / \mathrm{ml})$ that is specific for the carboxyl terminus of the rat GLUT4 (East-Acres Biologicals, Southbridge, MA [25]) or the polyclonal antibody A379 (gift of Dr. S. Cushman) that is specific for the carboxyl terminus of the rat brain GLUT1 (26), followed by incubation with ${ }^{125}$ I-labeled protein A (Amersham Corp., Arlington Heights, IL). The nitrocellulose membranes were then exposed to Kodak XAR-5 film at $-80^{\circ} \mathrm{C}$ for $16-48 \mathrm{~h}$. Bands corresponding to specific glucose transporters were quantitated by video densitometry. For each gel, serial dilutions of a microsomal membrane stock were run as an internal standard to allow a comparison of samples run in separate gels and to determine linearity.

We also attempted to determine the relative amounts of GLUT1 and GLUT4 in the membranes fractions using the method of Calderhead et al. (27) for quantitative immunoblotting. In this approach, serial dilutions of the internal standard (used above) were analyzed for each isoform by comparison with a GLUT1 standard (human erythrocyte ghost membranes) and a GLUT4 standard (rat adipocyte lowdensity microsomal membranes) and then compared to the isoform levels of the membranes quantified in the original Western blots. Human erythrocyte ghosts were prepared by the method of Baldwin and Lienhard (28) and basal rat adipocyte low-density microsomal membranes were prepared as described by Rodbell (29) and Cushman (30). Glucose transporter content of these standards were initially determined by cytochalasin B binding. The human erythrocyte ghosts contained $1,100 \mathrm{pmol}$ of cytochalasin $B$ binding sites per milligram protein which was calculated to be $\sim 5.5 \%$ of the membrane protein, similar to estimations in other laboratories (31). These membranes did not cross react with the GLUT4 antibody. Basal low-density microsomes contained $46 \mathrm{pmol}$ of cytochalasin B binding sites per milligram of protein. By comparative western blot analysis of these membranes, it was determined that GLUT1 accounted for 4 pmol of cytochalasin B binding sites per milligram of the microsomes or $8.7 \%$ of the total glucose transporters in these membranes, similar to the results of others $(32,33)$. Assuming that there was no or negligible contribution by other transporter isoforms in the microsomes and ghosts, and that all transporters can bind with cytochalasin B, GLUT4 protein in the low density microsomes was determined to be $42 \mathrm{pmol} / \mathrm{mg}$.

Steady-state mRNA measurements. Lean and obese Zucker rats under basal conditions were killed by decapitation. A sample of red gastrocnemius ( $\sim 500 \mathrm{mg}$ ) was removed, immediately frozen in liquid nitrogen, and stored at $-80^{\circ} \mathrm{C}$. Total tissue RNA was extracted using a guanidinium thiocyanate method (34). RNA was electrophoresed on $1.2 \%$ formaldehyde-agarose gels, blotted and fixed on to nitrocellulose filters, and then hybridized to a cDNA probe for the GLUT4 or "adipose-muscle" transporter (gift of Dr. Maureen Charron, Albert Einstein College of Medicine, Bronx, NY). The cDNA probe was a mixture of two fragments, a 1,500-basepair and a 750-basepair Eco RI-Pst I fragment, that together contain almost the full coding sequence and $3^{\prime}$ untranslated regions (35). The fragments were labeled with ${ }^{32} \mathrm{P}$ by oligolabeling (Pharmacia Inc., Piscataway, NJ) and the labeled probes were purified from unincorporated nucleotides by gel filtration on Sephadex G-50. Hybridization was carried out for $20 \mathrm{~h}$ at $42^{\circ} \mathrm{C}$ in a solution containing $50 \%$ formamide, $5 \times \mathrm{SSC}(0.75 \mathrm{M} \mathrm{NaCl}, 0.075 \mathrm{M}$ $\mathrm{Na}$ citrate, pH 7.0), $5 \mathrm{mM}$ EDTA, $0.1 \%$ SDS, $25 \mathrm{mM} \mathrm{NaH}_{2} \mathrm{PO}_{4}, 0.1$ 
$\mathrm{mg} / \mathrm{ml}$ calf thymus, and $0.1 \%$ of ficoll, bovine serum albumin, and polyvinyl pyrolidine. Blots were washed in $2 \times$ SSC and $0.1 \%$ SDS at $45-50^{\circ} \mathrm{C}$ for $15 \mathrm{~min}$ (three times). They were then exposed to Kodak film at $-80^{\circ} \mathrm{C}$ with an intensifying screen for 5-6 d. The relative abundance of the adipose-muscle glucose transporter (GLUT4) was quantified using a laser scanning densitometer (Biomed Instruments Inc., Fullerton, CA).

Statistical analysis. Data are expressed as the mean $\pm \mathrm{SE}$ and analyzed using Student's $t$ test. Significant differences between basal and insulin-treated states are indicated by $P$ values.

\section{Results}

Plasma glucose and insulin concentrations. At the time of sacrifice, blood was collected from each animal for measurement of plasma insulin and glucose concentration. In these postprandial lean Zucker rats, mean plasma glucose concentration was $122 \pm 7 \mathrm{mg} / \mathrm{dl}($ mean $\pm \mathrm{SE}, n=7)$ and mean plasma insulin was $24 \pm 6 \mu \mathrm{U} / \mathrm{ml}$. In the obese animals, plasma glucose concentrations were similar, $115 \pm 5.3 \mathrm{mg} / \mathrm{dl}(n=7)$, but plasma insulin levels averaged $141 \pm 32 \mu \mathrm{U} / \mathrm{ml}$, five to six times higher than the levels in the lean animals. Insulin treatment (see Methods) resulted in an increase in plasma insulin to $\geq 20 \mathrm{mU} / \mathrm{ml}$ for both lean and obese animals. This was associated with a decrease in plasma glucose to $59 \pm 6 \mathrm{mg} / \mathrm{dl}$ in the lean and $69 \pm 3$ $\mathrm{mg} / \mathrm{dl}$ in the obese rats at the time of sacrifice $30 \mathrm{~min}$ after i.p. insulin injection.

Enzymatic characterization of plasma membranes. The quality and purity of the final plasma membrane preparations were evaluated by the absence or presence of marker enzymes. Potassium-stimulated P-nitrophenyl phosphatase (KpNPPase) was used as a marker for the plasma membrane and $\mathrm{Ca}^{2+}$ ATPase as a marker for the sarcoplasmic reticulum. Activity was measured in the starting tissue homogenates and in the final membrane suspensions: the specific activities were compared to quantitate the relative enrichment. Table I shows the results of these assays. For the final membrane preparations, the KpNPPase specific activity was enriched $\geq 30$ fold as compared to activity in the homogenates and represented an

Table I. Enzymatic Characterization of Skeletal Muscle Plasma Membranes from Lean and Obese Zucker Rats

\begin{tabular}{|c|c|c|c|c|}
\hline & \multicolumn{2}{|c|}{ Lean rats } & \multicolumn{2}{|c|}{ Obese rats } \\
\hline & Basal & Insulin & Basal & Insulin \\
\hline \multicolumn{5}{|l|}{ KpNPPase } \\
\hline \multicolumn{5}{|l|}{ HM activity } \\
\hline $\mathrm{nmol} /(\mathrm{mg} \cdot \mathrm{min})$ & $5.1 \pm 0.6$ & $5.5 \pm 0.5$ & $4.4 \pm 0.4$ & $4.4 \pm 0.6$ \\
\hline \multicolumn{5}{|l|}{ PM activity } \\
\hline $\mathrm{nmol} /(\mathrm{mg} \cdot \mathrm{min})$ & $179 \pm 17$ & $216 \pm 24$ & $160 \pm 13$ & $145 \pm 5$ \\
\hline Enrichment & $34 \pm 5$ & $39 \pm 5$ & $37 \pm 5$ & $33 \pm 4$ \\
\hline \multicolumn{5}{|l|}{ Ca-ATPase } \\
\hline \multicolumn{5}{|l|}{ HM activity } \\
\hline $\mathrm{nmol} /(\mathrm{mg} \cdot \mathrm{min})$ & $226 \pm 32$ & $171 \pm 24$ & $204 \pm 25$ & $135 \pm 15$ \\
\hline \multicolumn{5}{|l|}{ PM activity } \\
\hline $\mathrm{nmol} /(\mathrm{mg} \cdot \mathrm{min})$ & $107 \pm 32$ & $91 \pm 32$ & $233 \pm 56$ & $151 \pm 39$ \\
\hline Enrichment & $0.6 \pm 0.3$ & $0.7 \pm 0.3$ & $1.2 \pm 0.3$ & $1.0 \pm 0.3$ \\
\hline
\end{tabular}

Values are the means $\pm \mathrm{SE}$ of seven or eight membrane preparations. HM, homogenate; PM, plasma membrane. Enrichment is the ratio of specific activity in the plasma membrane fraction to that in the homogenate.

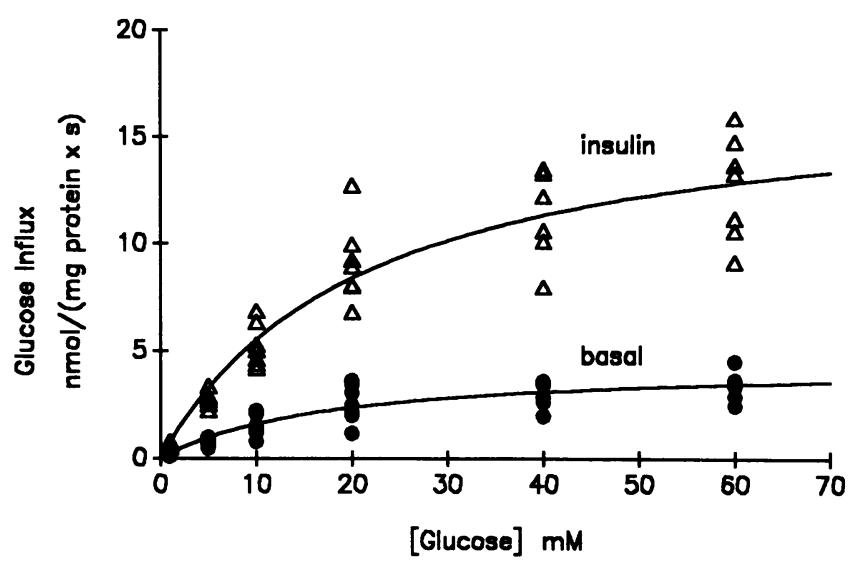

Figure 1. Carrier-mediated glucose influx versus glucose concentration for skeletal muscle plasma membrane vesicles isolated from basal and insulin-treated lean Zucker rats. Values are rates of D-glucose uptake minus rates of L-glucose uptake at each glucose concentration. The line is a nonlinear least-squares fit of the data.

8-12\% recovery of the total tissue KpNPPase activity. In comparison, the Ca-ATPase activity of the plasma membranes displayed a low enrichment $(0.6-1.2)$ that represented $\leq 0.08 \%$ of the total activity. There were no differences in the enzyme recoveries or enrichments between the treatment groups. These data indicate that the final membrane preparations were highly enriched in a plasma membrane marker with little contamination of sarcoplasmic reticulum.

Characteristics of glucose transport in plasma membrane vesicles from control and insulin-treated lean Zucker rats. Measurement of glucose uptake into membrane vesicles demonstrated that the carrier-mediated influx increased hyperbolically with increasing glucose concentration (Fig. 1), as previously shown for muscle membranes isolated from Sprague-Dawley rats (13). Facilitated transport in membranes isolated from the basal rats displayed a $V_{\max }$ of $4.5 \pm 0.4 \mathrm{nmol} /$ (mg $\cdot \mathrm{s}$ ) and a $K_{1 / 2}$ of $18 \pm 2.7 \mathrm{mM}$ (Table II). Cytochalasin B binding indicated $8.6 \pm 1.0$ pmol of transporter sites per milligram of protein $\left(R_{\mathrm{o}}\right)$ and a $K_{\mathrm{d}}$ of $116 \mathrm{nM}$ (Table II). The average carrier turnover number for the facilitated transporter, calculated from these data, was $525 \pm 73 / \mathrm{s}$.

Membranes from the insulin treated rats were characterized by a 3.9-fold greater $V_{\max }$ for transport [17.5 nmol/ ( $\mathrm{mg} \cdot \mathrm{s})$ ] but a similar $K_{1 / 2}$ (Fig. 1, Table II). The increase in $V_{\max }$ was associated with a 1.8 -fold increase in the number of transporter sites determined by cytochalasin B binding (15.7 $\pm 2.1 \mathrm{pmol} / \mathrm{mg}$ protein, Table II) and a doubling of the average carrier turnover number $(1,115 \pm 172 / \mathrm{s})$. An analysis of GLUT4 and GLUT1 protein levels in the plasma membranes, measured by immunoblotting using the R820 or A379 antibody, indicated that the increase in transporter sites was associated with a 1.4-fold rise in GLUT4 protein and no change in GLUT1 (Figs. 2 and 3). By comparison to GLUT4 and GLUT1 standards (see Methods), we estimate that the ratio of GLUT4/GLUT1 was $6.3 \pm 1.0$ in membranes from basal animals and $9.0 \pm 1.5$ in membranes from maximally stimulated rats. The mean vesicular volume, determined from the equilibrium measurements, was $5.0 \pm 0.3 \mu \mathrm{l} / \mathrm{mg}$ protein for vesicles from the basal animals and $5.5 \pm 0.2 \mu \mathrm{l} / \mathrm{mg}$ protein for vesicles from the insulin-treated lean rats. The agreement in vesicular volume indicates that a comparison of the transport 
Table II. Carrier-mediated Glucose Transport Characteristics of Skeletal Muscle Plasma Membrane Vesicles from Lean and Obese Zucker Rats

\begin{tabular}{|c|c|c|c|c|c|}
\hline & \multicolumn{2}{|c|}{ Glucose transport } & \multicolumn{2}{|c|}{ Cytochalasin B binding } & \multirow{2}{*}{$\begin{array}{l}\text { Carrier turnover } \\
\text { number }\end{array}$} \\
\hline & $V_{\max }$ & $K_{1 / 2}$ & $R_{0}$ & $K_{\mathrm{d}}$ & \\
\hline & $n m o l /(m g \cdot s)$ & $m M$ & $\mathrm{pmol} / \mathrm{mg}$ & $n M$ & $s^{-1}$ \\
\hline Lean basal (7) & $4.5 \pm 0.4$ & $18 \pm 2.7$ & $8.6 \pm 1.0$ & $116 \pm 12$ & $525 \pm 73$ \\
\hline \multirow[t]{2}{*}{ Lean insulin (8) } & $17.5 \pm 1.3$ & $22 \pm 3.7$ & $15.7 \pm 2.1$ & $140 \pm 14$ & $1115 \pm 172$ \\
\hline & $P<.001$ & N.S. & $P<.01$ & N.S. & $P<.01$ \\
\hline Obese basal (8) & $3.6 \pm 0.3$ & $21 \pm 3.3$ & $6.4 \pm 0.8$ & $91 \pm 5.5$ & $562 \pm 81$ \\
\hline \multirow[t]{2}{*}{ Obese insulin (8) } & $9.1 \pm 0.9$ & $21 \pm 4.3$ & $8.0 \pm 0.4$ & $104 \pm 8.4$ & $1137 \pm 122$ \\
\hline & $P<.001$ & N.S. & N.S. & N.S. & $P<.01$ \\
\hline
\end{tabular}

Values are the means $\pm \mathrm{SE}$ and $n$ is indicated in parentheses. The $V_{\max }$ and $K_{1 / 2}$ values were determined from nonlinear least squares fits of the data in Figs. 1 and 4 . Significant differences between values for membranes from basal versus insulin treated animals are indicated by $P$ values.

rates for the two treatments groups is not biased by differences in the quantity of protein associated with vesicle membranes vs. nonvesicle protein.

Characteristics of glucose transport in plasma membrane vesicles from basal and insulin-treated obese Zucker rats. Glucose transport was then studied in plasma membranes isolated from skeletal muscle of obese Zucker rats under basal or maximally insulin-treated conditions. For membranes from basal obese rats the $V_{\max }$ for carrier-mediated D-glucose uptake was $3.6 \pm 0.3 \mathrm{nmol} /(\mathrm{mg} \cdot \mathrm{s})$, and the $K_{1 / 2}$ was $21 \pm 3 \mathrm{mM}$, similar to values for the basal lean animals (Fig. 4, Table II). The number of transporter sites in the plasma membranes identified by CBbinding was $6.4 \pm 0.8 \mathrm{pmol} / \mathrm{mg}$ protein, again similar to membranes from the basal lean animals. The average glucose transporter carrier turnover number calculated from these data was $562 \pm 81 / \mathrm{s}$.

For the obese animals, insulin-treatment with maximally stimulating doses in vivo increased the $V_{\max }$ for facilitated glucose transport [ $9.1 \pm 0.9 \mathrm{nmol} /(\mathrm{mg} \cdot \mathrm{s})]$ but to a smaller degree than in the lean animals (Fig. 4, Table II). There was no change in the $K_{1 / 2}$. As found for the lean animals, the carrier

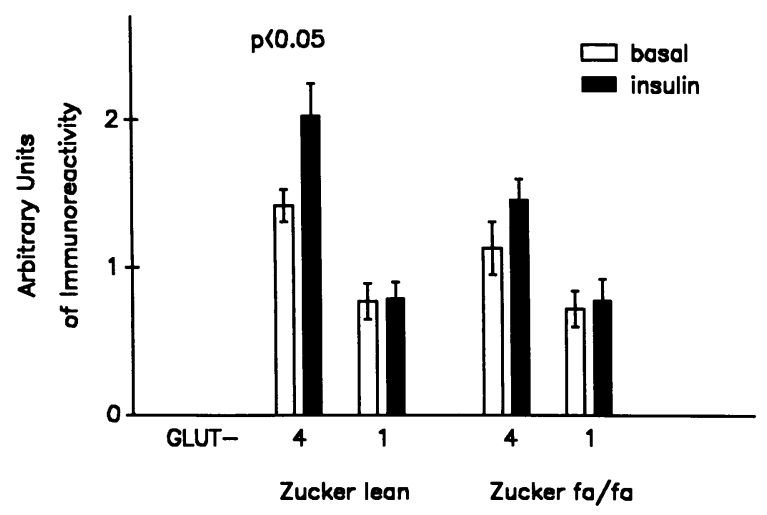

Figure 2. Comparison of the relative numbers of GLUT4 and GLUT1 transporters in membranes from basal and insulin-treated Zucker rats. The values are the means $\pm \mathrm{SE}$ of six to eight membrane preparations. Significant differences between membranes from basal versus insulin-treated rats are indicated by $P$ values. The immunoblotting was performed as described in Methods. A representative blot is shown in Fig. 3. turnover number increased with insulin treatment to $1137 \pm 122 / \mathrm{s}$. On the other hand unlike the changes seen for the lean rats, insulin treatment did not significantly increase the number of transporter sites in the plasma membrane measured by $C B$ binding and resulted in no significant change in the plasma membrane GLUT4 or GLUT1 protein (Figs. 2 and 3). We estimate GLUT4 and GLUT1 isoforms were present at GLUT4/GLUT1 ratios of $5.4 \pm 1.3$ for basal membranes, similar to ratios for the basal lean animals, and $6.5 \pm 1.3$ for membranes from insulin treated rats. There was no significant difference in the mean vesicular volumes, $4.2 \pm 0.6 \mu \mathrm{l} / \mathrm{mg}$ protein for membranes from the basal obese animals and $4.5 \pm 0.2 \mu \mathrm{l} /$ $\mathrm{mg}$ protein for membranes from the insulin-stimulated animals.

Verification of cytochalasin- $B$ sensitivity of carrier-mediated flux. In the present experiments, the carrier-mediated D-glucose transport was derived from the difference in the initial rate of D- vs. L-glucose influx using a dual radiolabel incubation, an approach having the advantage of requiring smaller amounts of membranes. The method assumes that D-glucose specific influx (total D-glucose influx minus L-glucose influx ) is completely inhibitable by cytochalasin $\mathrm{B}$, an assumption central to the comparison of cytochalasin B binding and transport rates, as in the calculation of turnover number. Therefore, additional experiments were performed to verify that the carriermediated flux obtained from the difference between the D- and L-glucose uptakes was the same as that obtained by measuring the rate of D-glucose influx in the absence and presence of a saturating concentration of cytochalasin B. The data in Table III show that for membranes from all of the groups, lean and obese animals, basal and insulin treated, the total carrier-mediated D-glucose influx was sensitive to inhibition by cytochalasin B.

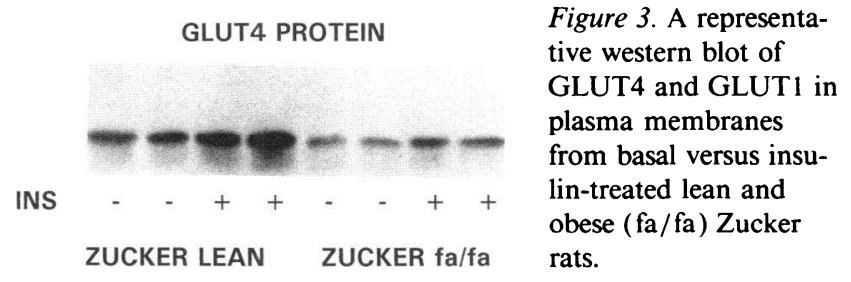




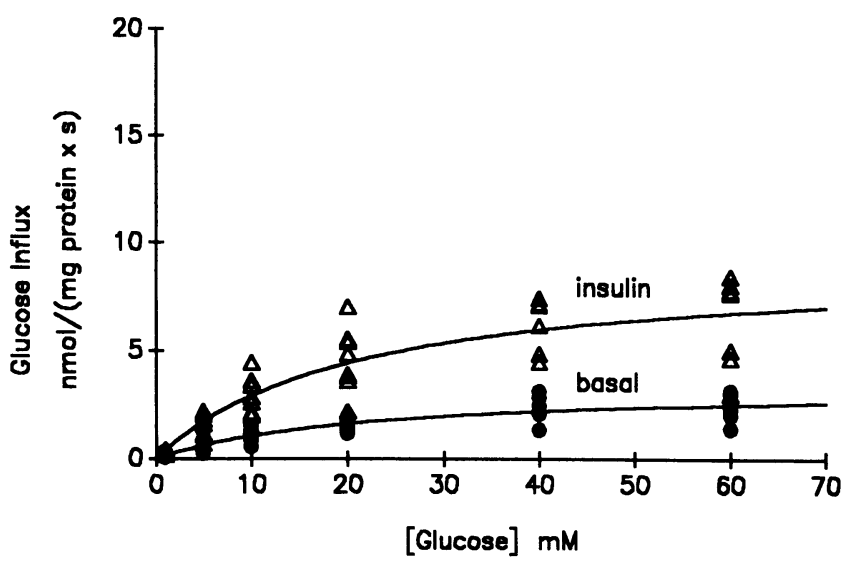

Figure 4. Carrier-mediated glucose influx versus glucose concentration for skeletal muscle plasma membrane vesicles isolated from basal and insulin-treated obese Zucker rats. Values are the rates of D-glucose uptake minus rates of L-glucose uptake at each glucose concentration. The line is a nonlinear least squares fit of the data.

Steady-state GLUT4 mRNA levels. RNA was isolated from red gastrocnemius muscle samples obtained from lean and obese animals under basal conditions. This muscle was chosen due to the fact that it represents a major fraction of the muscle used in the membrane preparation. The yield of total RNA was $0.68 \pm 0.08$ and $0.82 \pm 0.20 \mu \mathrm{g} / \mathrm{mg}$ tissue for muscle from lean and obese rats, respectively (mean $\pm \mathrm{SE}, n=4)$. Fig. 5 shows that the mRNA for the GLUT4 transporter in Zucker lean and obese gastrocnemius is identified as a $2.7-\mathrm{kb}$ mRNA. RNA from red gastrocnemius obtained from basal male SpragueDawley rats $(200 \mathrm{~g})$ was analyzed for comparison and shows no difference in size of the GLUT4 mRNA. Fig. 6 summarizes the relative abundance of GLUT4 transporter mRNA in red gastrocnemius samples from four lean and four obese Zucker rats. The densitometry scans revealed no difference in the mean area of the GLUT4 mRNA peaks for these two groups.

Table III. Effect of Cytochalasin B on Carrier-mediated Glucose Transport in Skeletal Muscle Plasma Membrane Vesicles from Zucker Rats

\begin{tabular}{ccccc}
\hline & & \multicolumn{3}{c}{ Influx } \\
\cline { 4 - 5 } Animals & Cytochalasin B & D-Glucose & L-Glucose & Carrier-mediated \\
\hline \multirow{3}{*}{ Lean basal } & & \multicolumn{3}{c}{$n \mathrm{nml} /(\mathrm{mg} \cdot \mathrm{s})$} \\
& - & 0.89 & 0.19 & 0.70 \\
Lean insulin & + & 0.18 & 0.19 & 0 \\
& - & 4.1 & 0.33 & 3.8 \\
Obese basal & + & 0.31 & 0.33 & 0 \\
& - & 0.90 & 0.18 & 0.72 \\
Obese insulin & + & 0.18 & 0.21 & 0 \\
& - & 1.4 & 0.30 & 1.10 \\
& + & 0.20 & 0.19 & 0 \\
\hline
\end{tabular}

Values are the means of influx measurements for two membrane preparations with influx assayed in the presence and absence of 25 $\mu \mathrm{M}$ cytochalasin B. D- and L-glucose were present at a concentration of $5 \mathrm{mM}$. The carrier-mediated flux is calculated as the difference between the rates of $\mathrm{D}$ - and $\mathrm{L}$-glucose influx.
Figure 5. Identification of GLUT4 mRNA in skeletal muscle of lean and obese Zucker rat. Northern blot analysis of red gastrocnemius skeletal muscle RNA ( $30 \mu \mathrm{g}$ per lane) from individual rats was performed as described in Methods. Zucker lean, Zucker obese, and Sprague-Dawley rats are compared. The position of the $28 \mathrm{~S}$ and $18 \mathrm{~S}$ ribosomal RNAs are shown and the arrow indicates the 2.7to $2.8-\mathrm{kb}$ glucose transporter mRNA.

\section{Discussion}

Skeletal muscle is the major site of insulin-mediated glucose transport accounting for $\sim 90 \%$ of the insulin-mediated glucose disposal $(36,37)$. An understanding of the regulation of glucose transport in this tissue is of central importance in elucidating the action of insulin to regulate glucose metabolism. The approach of using animal models of insulin resistance, such as the obese Zucker rat, serves not only to identify potential sites where transport and its regulation are altered in insulin resistance but also provides insight into the normal process of glucose transport and its regulation. The goal of our experiments was to determine if the insulin resistance of obese rat skeletal muscle resulted from alteration in the action of insulin to simulate transporter translocation and / or the average transporter activity and if possible to learn more about the interdependence of these two phenomena.

In lean Zucker rat skeletal muscle insulin treatment resulted in a fourfold increase in $V_{\max }$ due to a near doubling of

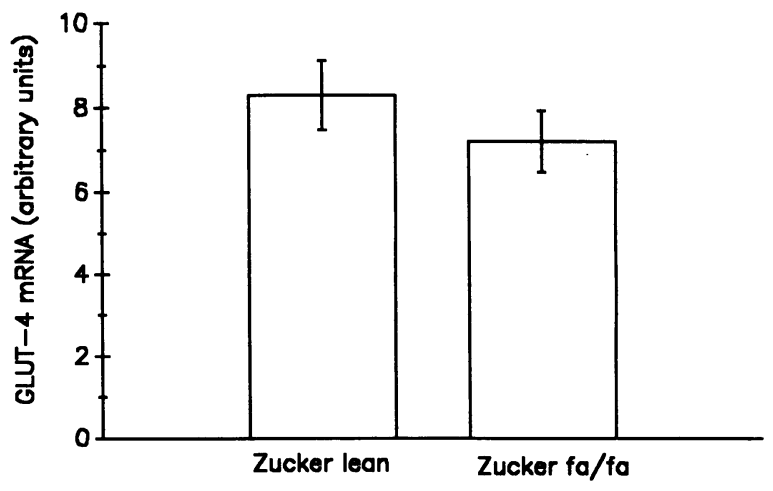

Figure 6. Comparison of the relative quantity of GLUT4 mRNA in red gastrocnemius skeletal muscle from lean and obese Zucker rats under basal physiological conditions. Northern blot analysis was performed as described in Methods and Fig. 4. The values are the means \pm SE of the GLUT4 mRNA in RNA isolated from four lean and four obese Zucker rats. 
the plasma membrane transporter number (cytochalasin B binding) and a doubling of the average carrier turnover number. Thus changes in the number and activity of the transporters in the plasma membrane contributed equally to the insulin stimulation of transport, results quantitatively similar to those previously reported for the effects of insulin or exercise on skeletal muscle glucose transport in Sprague-Dawley rats $(9,13)$. The mean carrier turnover number for the glucose transporters under basal physiological conditions was $525 \pm 73 / \mathrm{s}$. This value is very similar to the number we have identified for glucose transporters in Sprague-Dawley skeletal muscle (700/s) and to that reported for GLUT1 in the human red blood cell $(645 / \mathrm{s})$ under similar conditions of measurement, equilibrium exchange and $25^{\circ} \mathrm{C}(38)$. Because our quantitation of the GLUT4/GLUT1 ratios indicated that at least $80 \%$ of the glucose transporters in the isolated membranes were the GLUT4 isoform, these data suggest that the basal turnover rate of GLUT4 is similar to that of GLUT1. However, definitive quantitation of the GLUT4 turnover number will ultimately require a more purified preparation of the isoform.

A major finding of the present study is that unlike in the lean rat, insulin treatment of the obese rat muscle results in no change in the number of transporters in the isolated plasma membranes. This occurs despite the fact that under their respective basal physiological conditions the obese Zucker rat (basal plasma insulin $=141 \mu \mathrm{U} / \mathrm{ml}$ ) skeletal muscle plasma membranes have approximately an equal number of glucose transporters as compared to it's lean litter mate (basal plasma insulin $=24 \mu \mathrm{U} / \mathrm{ml}$ ). A similar but less severe defect in the action of insulin to stimulate muscle transporter translocation has been reported for another model of insulin resistance, streptozotocin-diabetic rats (39). The carrier turnover numbers in the basal states are also similar in the obese versus lean rat, but insulin treatment increases the turnover number to an equal degree, approximately twofold, in both Zucker strains, indicating that the action of maximally stimulating concentrations of insulin to increase the average transporter turnover number functions normally in the obese animals. The present study investigated glucose transport characteristics under basal physiological and maximally stimulating insulin doses only. Unfortunately, little is known of the insulin dose response of translocation versus changes in transporter activity in skeletal muscle.

As previously reported $(9,13)$, we found no change in the $K_{1 / 2}$ for facilitated glucose transport with insulin treatment. However, it must be noted that if glucose transporters in the muscle are characterized by a significant asymmetry, it is possible that changes in affinity at one side of the membrane are not detected by the equilibrium exchange measurements made here.

Previous investigations have examined the effects of insulin on Zucker rat skeletal muscle glucose transport using the perfused hindlimb preparation $(6,40)$, and provide some comparison for the relative changes in glucose flux rates observed with insulin stimulation in the present study. Sherman et al. (6) found that glucose uptake by the whole hindlimb in the obese Zucker rat increased 2.5-fold with an increase in perfusion insulin from 150 to $15,000 \mu \mathrm{U} / \mathrm{ml}$. In the lean Zucker rats, hindlimb glucose uptakes increased approximately fourfold when increasing the perfusing insulin concentration from 25 to $15,000 \mu \mathrm{U} / \mathrm{ml}$. If measured as $3-0$-methylglucose uptake by the gastrocnemius ( the major muscle group represented in the membrane preparation), the authors found uptake increased 2.5-fold for the obese rat and 5-6-fold for the lean rat. Thus the relative changes in transport that are observed for the isolated membranes are similar to those previously reported for the intact perfused muscle.

The changes in turnover number or intrinsic activity of the glucose transporter associated with insulin and/or exercise stimulation are not well understood. Experiments with animal models, e.g., insulin-treated streptozotocin diabetic rat and the fasted-refed rat, and, more recently, with fibroblasts and 3T3$\mathrm{L} 1$ adipocytes have provided evidence that transport is controlled by changes in carrier activity as well as carrier number (41-46). On the other hand, other studies, including immunocytochemical studies, have demonstrated that transporter translocation can account for the total increase in glucose with insulin stimulation $(47,48)$. In our approach the average carrier turnover number is measured and, as a result, changes in activity could result due to a modification of all or some of the carriers or the recruitment of a more active carrier. The data from the obese Zucker rat indicate that insulin stimulates an increase in transporter activity in the absence of a change in the total number of transporters (CB binding) or in membrane GLUT4 protein. These results suggest that activation is independent of translocation and does not represent the recruitment of a more active form of the carrier. Instead, the changes in carrier turnover number would result from a modification of the activity of some or all of the transporters already present in the membrane, but the biochemical or biophysical mechanism is unknown. Alternatively, we cannot exclude the possibility that there may be an additional, non-GLUT4 or GLUT1, glucose transporter translocated to the plasma membrane in low quantity but with very high activity. Nor can we rule out the interpretation that the nonsignificant increases in membrane cytochalasin B binding and GLUT4 immunoreactivity with insulin treatment may account for the smaller changes in $V_{\max }$ values for the obese animals.

The failure of insulin to promote a translocation of transporters in the obese rat skeletal muscle could involve one or more of the steps involved in this process including defects in post-binding receptor signaling, the size of the intracellular pool, or the translocation process itself. Studies in adipose cells have indicated that, at least for this tissue, the size of the intracellular pool is an important determinant of the response of glucose transport to insulin (49). In animal models of insulin resistance, failure of quantitative recruitment of transporters to the plasma membrane upon insulin stimulation of the fat cells is associated with a decrease in the number of glucose transporters in the low density microsomes $(41,50-53)$, whereas models of hyperresponsiveness, including the fat cell of young obese Zucker rats (54), are associated with increased amounts of intracellular transporters $(53,55)$. The results of similar studies in skeletal muscle are mixed. In the streptozotocin diabetic rat, skeletal muscle is characterized by decreased transporter number (56), GLUT4 protein, and GLUT4 mRNA (57). However, muscle of fasted rats appears to have increased levels of GLUT4 mRNA ( 53) and protein $(53,57)$ and skeletal muscle of the obese insulin-resistant $\mathrm{db} / \mathrm{db}$ mouse (15) has normal GLUT4 protein levels as compared to their lean litter mates. For the Zucker rat, Friedman et al. (14) have reported no difference in the level of GLUT4 protein in skeletal muscle of the lean versus obese animals and, in the present study, we find no difference in the red gastrocnemius GLUT4 mRNA levels. 
Thus, the insulin resistance of obese Zucker rat skeletal muscle, like that of muscle in the $\mathrm{db} / \mathrm{db}$ mouse and fasted animals, does not appear to be due to a reduced pool of intracellular transporters.

A second location for the defect of insulin action is the transduction of the hormone signal from the insulin receptor, including the possible involvement of receptor tyrosine kinase activity. Slieker et al. (58) have reported that the muscle of the obese Zucker rat displays a significant decrease in the insulin receptor autophosphorylation and tyrosine kinase activity as compared to muscle of the lean litter mates. Similar defective tyrosine kinase activity has been reported for skeletal muscle from insulin-resistant obese mice (59) and obese human subjects (60), suggesting that these alterations are of general importance in the etiology of skeletal muscle insulin resistance. In addition, changes in protein kinase $\mathrm{C}$ activity and cellular localization have been associated with insulin action. To this end, Van de Werve et al. (61) have found defects in protein kinase activity in the cardiac muscle of obese Zucker rats. It should be noted that if the insulin stimulated increase in transporter activity is, in fact, independent of carrier translocation, then the present data suggest that translocation and activation may involve different aspects of the insulin receptor function. Dissociation of insulin receptor functions has been previously demonstrated for metabolic versus growth signalling actions of the receptor $(62,63)$.

Finally, the failure of insulin to stimulate the translocation of transporters to the membrane in these obese animals could be due to defects in the translocation process itself, i.e., the cellular factors or conditions required for moving the intracellular microsomal population into the membrane. Such steps may involve processes of vesicle translocation or errors in the posttranslational processing of the transporters required for normal translocation to the plasma membrane. Horuk et al. (64) have reported that fat cell glucose transporters in the intracellular pool exist in at least two molecular forms with different glycosylation characteristics and isoelectric points, and that only one of these forms is translocated by insulin.

It is possible that the apparent insulin resistance of the obese Zucker reflects both the response to insulin and to counterregulatory hormones. In adipose cells and fibroblasts (65, 66 ), glucocorticoids have been demonstrated to stimulate the reverse translocation of glucose transporters. If there is a similar effect in skeletal muscle, a greater release of corticosterone with insulin stimulation or a greater sensitivity to this hormone could result in a decrease in the net translocation of transporters. Preliminary measurements of plasma corticosterone concentrations indicate that insulin treatment does not result in a greater release of this hormone in obese versus lean animals. But these data do not exclude the possibility that the skeletal muscle glucose transport system is more responsive to this hormone (67). The role of the counterregulatory hormones in the net movement of transporters and transporter recycling awaits further study.

In summary, we have demonstrated that the defect in insulin's ability to stimulate glucose transport in obese Zucker rat skeletal muscle is due to a failure of carriers to translocate to the cell membrane, while the action of insulin to increase the average turnover number of the plasma membrane transporters is intact. These data suggest that the insulin-stimulated increase in the average carrier turnover number may occur independently of the recruitment of new carriers to the membrane.

\section{Acknowledgments}

We thank Dr. M. Charron for the gift of GLUT-4 cDNA, Dr. S. Cushman for the gift of A379 antibody, and Drs. M. Periasamy and P. Babij for assistance in preparation of the cDNA probes and Northern analysis. We also thank $P$. Mead for performing the insulin radioimmunoassays and $\mathrm{L}$. Del Hagen for assistance in the preparation of the manuscript.

The work was supported by the National Institute of Diabetes and Digestive and Kidney Diseases grant RO1-DK-26317.

\section{References}

1. Bray, G. A. 1977. The Zucker-fatty rat: a review. Fed. Proc. 36:148-153.

2. Ionescu, E., J. F. Sauter, and B. Jeanrenaud. 1985. Abnormal oral glucose tolerance in genetically obese (fa/fa) rats. Am. J. Physiol. 248:E500-E506.

3. Kemmer, F. W., M. Berger, L. Herberg, F. A. Gries, A. Wirdeier, and K. Becker. 1979. Glucose metabolism in perfused skeletal muscle: demonstration of insulin resistance in obese Zucker rat. Biochem. J. 178:733-741.

4. Crettaz, M., M. Prentki, D. Zaninetti, and B. Jeanrenaud. 1980. Insulin resistance in soleus muscle from obese Zucker rats: involvement of several defective sites. Biochem. J. 186:525-534.

5. Czech, M. P., D. K. Richardson, S. G. Becker, C. G. Walters, W. Gitomer, and J. Heinrich. 1978. Insulin response in skeletal muscle and fat cells of the genetically obese Zucker rat. Metab. Clin. Exp. 27:1967-1981.

6. Sherman, W. M., A. L. Katz, C. L. Cutler, R. T. Withers, and J. L. Ivy. 1988. Glucose transport: locus of muscle insulin resistance in obese Zucker rats. Am. J. Physiol. 255:E374-E382.

7. Wardzala, L. J., and B. Jeanrenaud. 1983. Identification of the D-glucoseinhibitable cytochalasin B binding site as the glucose transporter in rat diaphragm plasma and microsomal membranes. Biochim. Biophys. Acta. 730:49-56.

8. Klip, A., T. Ramlal, D. A. Young, and J. O. Holloszy. 1987. Insulin-induced translocation of glucose transporters in rat hindlimb muscles. FEBS (Fed. Eur. Biochem. Soc.) Lett. 224:224-230.

9. Sternlicht, E., R. J. Barnard, and G. K. Grimditch. 1988. Mechanism of insulin action on glucose transport in rat skeletal muscle. Am. J. Physiol. 254:E633-E638.

10. Hirshman, M. F., L. J. Goodyear, L. J. Wardzala, E. D. Horton, and E. S. Horton. 1990. Identification of an intracellular pool of glucose transporters from basal and insulin-stimulated rat skeletal muscle. J. Biol. Chem. 265:987-991.

11. Douen, A. G., T. Ramlal, S. Rastogi, P. J. Bilan, G. D. Cartee, M. Vranic, J. O. Holloszy, and A. Klip. 1990. Exercise induces recruitment of the "insulinresponsive glucose transporter." J. Biol. Chem. 265:13427-13430.

12. Rodnick, K. J., G. W. Slot, D. R. Studelska, D. E. Hampter, L. J. Robinson, H. J. Geuze, and D. E. James. 1992. Immunocytochemical and biochemical studies of GLUT4 in rat skeletal muscle. J. Biol. Chem. 267:6278-6285.

13. King, P. A., M. F. Hirshman, E. D. Horton, and E. S. Horton. 1989. Glucose transport in skeletal muscle membrane vesicles from control and exercised rats. Am. J. Physiol. 257:C1128-C1134.

14. Friedman, J. E., W. M. Sherman, M. J. Reed, C. W. Elton, and G. L. Dohm. 1990. Exercise training increases glucose transporter protein GLUT-4 in skeletal muscle of obese Zucker (fa/fa) rats. FEBS (Fed. Eur. Biochem. Soc.) Lett. 268:13-16.

15. Koranyi, L., D. James, M. Mueckler, and A. Permutt. 1990. Glucose transporter levels in spontaneously obese $(\mathrm{db} / \mathrm{db})$ insulin-resistant mice. J. Clin. Invest. 85:962-967.

16. Kahn, B. B., L. Rossetti, H. F. Lodish, and M. J. Charron. 1991. Decreased in vivo glucose uptake but normal expression of GLUT1 and GLUT4 in skeletal muscle of diabetic rats. J. Clin. Invest. 87:2197-2206.

17. Bers, D. M. 1979. Isolation and characterization of cardiac sarcolemma. Biochim. Biophys. Acta. 555:131-146.

18. Grimditch, G. K., R. J. Barnard, S. A. Kaplan, and E. Sternlicht. 1985 Insulin binding and glucose transport in rat skeletal muscle sarcolemmal vesicles. Am. J. Physiol. 249:E398-E408.

19. Seiler, S., and S. Fleischer. 1982. Isolation of plasma membrane vesicles from rabbit skeletal muscle and their use in ion transport studies. J. Biol. Chem. 257:13862-13871.

20. Bradford, M. M. 1976. A rapid and sensitive method for the quantitation of microgram quantities of protein utilizing the principle of protein-dye binding. Anal. Biochem. 72:248-254.

21. Wardzala, L. J., S. W. Cushman, and L. B. Salans. 1978. Mechanism of insulin action on glucose transport in the isolated rat adipose cell: enhancement of the number of functional transport systems. J. Biol. Chem. 253:8002-8005.

22. Wilkinson, G. N. 1961. Statistical estimations in enzyme kinetics. Biochem. J. 80:324-332.

23. Laemmli, V. K. 1970. Cleavage of structural proteins during the assembly of the head of bacteriophage $T_{4}$. Nature (Lond.). 227:680-685.

24. Towbin, H., T. Staehelin, and J. Gordon. 1974. Electrophoretic transfer of 
proteins from polyacrylamide gels to nitrocellulose sheets: procedure and some applications. Proc. Natl. Acad. Sci. USA. 76:4350-4354.

25. James, D. E., M. Strube, and M. Mueckler. 1989. Molecular cloning and characterization of an insulin-regulatable glucose transporter. Nature (Lond.) 338:83-87.

26. Haspel, H. C., M. G. Rosenfeld, and O. M. Rosen. 1988. Characterization of antisera to a synthetic carboxyl-terminal peptide of the glucose transporter protein. J. Biol. Chem. 263:398-403.

27. Calderhead, D. M., K. Kitagawa, L. Tanner, G. Holman, and G. Lienhard. 1990. Insulin regulation of the two glucose transporters in 3T3-L1 adipocytes. J. Biol. Chem. 265:13800-13808.

28. Baldwin, S., and G. Lienhard. 1989. Purification and reconstitution of glucose transporter from human erythrocytes. Methods Enzymol. 174:39-49.

29. Rodbell, M. 1964. Metabolism of isolayed fat cells. I. Effects of hormones on glucose metabolism and lipolysis. J. Biol. Chem. 239:375-380.

30. Cushman, S. 1970. Structure-function relationship in the adipose cell. I. Ultrastructure of the isolated adipose cell. J. Cell Biol. 46:326-341.

31. Allard, W., and G. Lienhard. 1985. Monoclonal autobodies to the glucose transporter from human. J. Biol. Chem. 260:8668-8675.

32. Gougos, A., and M. Letarte. 1988. Biochemical characterization of the 44G4 antigen from the hoon pre-b leukemic cell line. J. Immunol. 141:1934 1940.

33. Oka, Y., T. Asano, Y. Shibasaki, M. Kasuga, Y. Kanazawa, and F. Takaku. 1988. Studies with antipeptide suggest the presence of at least two types of glucose transporter in rat brain and adipocyte. J. Biol. Chem. 263:13432-13439.

34. Chomczynski, P., and N. Sacchi. 1987. Single step method of RNA isola-

tion by acid guanidinium thiocyanate-phenol-chloroform extraction. Anal. Biochem. 162:156-159.

35. Charron, M. J., F. C. Brosius III, S. L. Alper, and H. F. Lodish. 1989. A glucose transport protein expressed predominantly in insulin-responsive tissues. Proc. Natl. Acad. Sci. USA. 86:2535-2539.

36. DeFronzo, R. 1988. The triumvirate: beta cell, muscle, liver. A collusion responsible for NIDDM. Diabetes. 37:667-687.

37. Garvey, T., and O. Kolterman. 1988. Correlation of in vivo and in vitro actions of insulin in obesity and noninsulin-dependent diabetes mellitus: role of glucose transport system. Diabetes Metab. Rev. 4:543-569.

38. Stein, W. 1986. Transport and Diffusion Across Cell Membranes. Academic Press, Ltd., London. 685 pp.

39. Barnard, R. J., J. F. Youngren, D. S. Kartel, and D. A. Martin. 1990. Effects of streptozotocin-induced diabetes on glucose transport in skeletal muscle. Endocrinology. 126:1921-1926.

40. Ivy, J., J. Brozinick, C. Torgan, and G. Kastello. 1989. Skeletal muscle glucose transport in obese Zucker rats after exercise training. J. Appl. Physiol. 66:2635-2641.

41. Kahn, B. B., I. A. Simpson, and S. W. Cushman. 1988. Divergent mechanisms for the insulin resistant and hyperresponsive glucose transport in adipose cells from fasted and refed rats. J. Clin. Invest. 82:691-699.

42. Kahn, B. B., and S. Cushman. 1987. Mechanism for markedly hyperresponsive insulin-stimulated glucose transport activity in adipose cells from insulin-treated streptozotocin diabetic rats. J. Biol. Chem. 262:5118-5124.

43. Clancy, B., and M. Czech. 1990. Hexose transport stimulation and membrane redistribution of glucose transporter isoforms in response to cholera toxin, dibutyryl cyclic AMP, and insulin in 3T3-L1 adipocytes. J. Biol. Chem. 265:12434-12443.

44. Clancy, B., S. Harrson, J. Buxton, and M. Czech. 1991. Protein synthesis inhibitors activate glucose transport without increasing plasma membrane glucose transporters in 3T3-L1 adipocytes. J. Biol. Chem. 266:10122-10130.

45. Harrison, S., J. Buxton, B. Clancy, and M. Czech. 1991. Evidence that erythroid-type transporter intrinsic activity is modulated by cadmium treatment of mouse 3T3-L1 cells. J. Biol. Chem. 266:19438-19449.

46. Harrison, S., J. Buxton, and M. Czech. 1991. Supressed intrinsic catalytic activity of GLUT1 glucose transporters in insulin-sensitive 3T3-L1 adipocytes. Proc. Natl. Acad. Sci. USA. 88:7839-7843.

47. Slot, J., H. Geuze, S. Gigengack, D. James, and G. Lienhard. 1991. Trans- location of the glucose transporter GLUT4 in cardiac myocytes of the rat. Proc. Natl. Acad. Sci. USA. 88:7815-7819.

48. Holman, G., I. Kozka, A. Clark, C. Flower, J. Saltis, A. Habberfield, I. Simpson, and S. Cushman. 1990. Cell surface labeling of glucose transporter isoform GLUT4 by bis-mannose photolabel. J. Biol. Chem. 240:3493-3500.

49. Kahn, B., and S. Cushman. 1985. Subcellular translocation of glucose transporters: role in insulin action and its pertubation in altered metabolic states. Diabetes Metab. Rev. 1:203-227.

50. Hissin, P. J., E. Karnieli, I. A. Simpson, L. B. Salans, and S. W. Cushman 1982. A possible mechanism of insulin resistance in the rat adipose cell with high-fat/low-carbohydrate feeding. Diabetes. 31:589-592.

51. Hissin, P. J., J. E. Foley, L. J. Wardzala, E. Karnieli, I. A. Simpson, L. B. Salans, and S. W. Cushman. 1982. Mechanism of insulin-resistant glucose transport activity in the enlarged adipose cell of the aged, obese rat. J. Clin. Invest. 70:780-790.

52. Karnieli, E., P. J. Hissin, I. A. Simpson, L. B. Salans, and S. W. Cushman. 1981. A possible mechanism of insulin resistance in the rat adipose cell in streptozotocin-induced diabetes mellitus. J. Clin. Invest. 68:811-814.

53. Charron, M. J., and B. B. Kahn. 1990. Divergent molecular mechanisms for insulin-resistant glucose transport in muscle and adipose cells in vivo. J. Biol. Chem. 265:7994-8000.

54. Guerre-Millo, M., M. Lavau, J. S. Horne, and L. J. Wardzala. 1985 Proposed mechanism for increased insulin-mediated glucose transport in adipose cells from young, obese Zucker rats. J. Biol. Chem. 260:2197-2201.

55. Kahn, B. B., E. S. Horton, and S. W. Cushman. 1987. Mechanism for enhanced glucose transport response to insulin in adipose cells from chronically hyperinsulinemic rats. J. Clin. Invest. 79:853-858.

56. Ramlal, T., S. Rastogi, M. Vranic, and A. Klip. 1989. Decrease in glucose transporter number in skeletal muscle of mildly diabetic (streptozotocin-treated) rats. Endocrinology. 25:890-897.

57. Bourey, R. E., L. Koranyi, D. E. James, M. Mueckler, and M. A. Permutt. 1990. Effects of altered glucose homeostasis on glucose transporter expression in skeletal muscle of the rat. J. Clin. Invest. 86:542-547.

58. Slieker, L. J., E. F. Roberts, W. W. Shaw, and W. T. Johnson. 1990. Effect of streptozotocin-induced diabetes on insulin-receptor tyrosine kinase activity in obese Zucker rats. Diabetes. 39:619-625.

59. Le Marchand-Brustel, Y., T. Grémeaux, R. Ballotti, and E. Van Obberghen. 1985. Insulin receptor tyrosine kinase is defective in skeletal muscle of insulin-resistant obese mice. Nature (Lond.). 315:676-679.

60. Arner, P., T. Pollare, H. Lithell, and J. N. Livingston. 1987. Defective insulin receptor tyrosine kinase in human skeletal muscle in obesity and type II (non-insulin-dependent) diabetes mellitus. Diabetologia. 30:437-440.

61. Van de Werve, G., D. Zaninetti, U. Lang, M. Vallotton, and B. Jeanrenaud. 1987. Identification of a major defect in insulin-resistant tissues of genetically obese ( $\mathrm{fa} / \mathrm{fa}$ ) rats. Impaired protein kinase C. Diabetes. 36:310-314.

62. Thies, R. S., A. Ullrich, and D. McClain. 1989. Augmented mitogenesis and impaired metabolic signaling mediated by a truncated insulin receptor. $J$. Biol. Chem. 264:12820-12825.

63. McClain, D. A., H. Maegawa, R. S. Thies, and J. M. Olefsky. 1990 Dissection of the growth versus metabolic effects of insulin and insulin-like growth factor-I in transfected cells expressing kinase-defective human insulin receptors. J. Biol. Chem. 265:1678-1682.

64. Horuk, R., S. Matthaei, J. M. Olefsky, D. L. Baly, S. W. Cushman, and I. Simpson. 1986. Biochemical and functional heterogeneity of rat adipocyte glucose transporters. J. Biol. Chem. 261:1823-1828.

65. Carter-Su, C., and K. Okamoto. 1985. Effect of glucocorticoids on hexose transport in rat adipocytes: evidence for decreased transporters in the plasma membrane. J. Biol. Chem. 260:11091-11098.

66. Horner, H., A. Munck, and G. Lienhard. 1987. Dexamethasone causes translocation of glucose transporters from the plasma membrane to an intracellular site in human fibroblasts. J. Biol. Chem. 262:17696-17702.

67. Freedman, M. R., B. A. Horowitz, and J. S. Stern. 1986. Effect of adrenalectomy and glucocorticoid replacement on development of obesity. Am. J. Physiol. 250:R595-R607. 